\title{
La no-americanización del proceso penal continental europeo: Del trasplante a la traducción jurídica en Langer
}

\author{
The Non-Americanization of the Continental \\ European Criminal Process: From Transplants to \\ Legal Translations in Langer
}

Lorena Bachmaier*

Recepción y evaluación de propuesta: 25/7/18

Aceptación: 20/8/18

Recepción y aceptación final: 29/10/18

Resumen: Si en el pasado la exportación o trasplante de normas jurídicas tenía lugar fundamentalmente a través de las invasiones bélicas, las conquistas políticas o los movimientos migratorios, actualmente las transferencias jurídicas transitan mayoritariamente por otras sendas. En un mundo globalizado la interacción entre sistemas es cada vez más intensa y las reformas legislativas no pueden mantenerse ajenas a lo que sucede en el entorno. Por ello el derecho comparado es en la actualidad más relevante que nunca. Al hilo del excelente trabajo de Máximo Langer "De los trasplantes a las traducciones legales", intentaré aportar algunas reflexiones acerca del recurso a las metáforas a la hora de definir esas relaciones entre sistemas y acerca de algo que puede parecer obvio: que la adopción de cualquier solución procesal —en este caso la justicia negociada - no puede deslindarse del contexto institucional en el que se aplica. El término propuesto por Langer de "traducción jurídica" capta perfectamente esa realidad.

Palabras clave: derecho comparado, proceso penal, trasplantes legales, plea-bargaining, justicia negociada, sistema adversarial, acusatorio, inquisitivo, verdad. 


\begin{abstract}
In the past the legal transplant took place mainly by way of military invasions, political conquests or migratory movements, but this has changed in the present globalized world. The interaction between systems is unavoidable and legal reforms at national as well as at supranational level cannot remain alien to the legal solutions adopted in other countries and organizations. This explains the increasing importance of comparative law. This paper seeks to enter into a dialogue with the excellent work of Máximo Langer "From legal transplants to legal translations...", with the aim of trying to contribute to some of the topics the author addresses in his work. In particular I will try to reflect on the use of metaphors when defining the relationships between legal systems. Further I will argue that the import of any procedural solution -in this case the negotiated justice- needs to be adjusted to the institutional context in which it will be applied. The term proposed by Langer of "legal translation" perfectly captures that reality.

Keywords: comparative law, criminal procedure, legal transfers, plea-bargaining, negotiated justice, adversary system, inquisitorial system, truth.
\end{abstract}

\title{
1. Introducción
}

El trabajo de Máximo Langer "De los trasplantes legales a las traducciones legales: la globalización del plea bargaining y la tesis de la 'americanización' en el proceso penal" ${ }^{1}$ nos adentra, a través del estudio de cuatro sistemas de justicia negociada, en el tema, permanentemente controvertido, de las influencias y transferencias entre sistemas jurídicos. Si en el pasado la exportación de sistemas jurídicos tenía lugar fundamentalmente a través de las invasiones bélicas, las conquistas políticas o los movimientos migratorios, actualmente las transferencias jurídicas transitan mayoritariamente por otras sendas. La globalización, los sistemas regionales de integración política - como la Unión Europea - y los programas de cooperación internacional representan nuevos y poderosos canales de transmisión de soluciones y modelos jurídicos. En el presente contexto, la función del comparatista adquiere una indudable relevancia, pues el estudio del dere-

1 En este número de Discusiones. Publicado originalmente en Harvard International Law Journal, 45, 2004, p. 1-64. 
La no-americanización del proceso penal continental europeo

cho no puede limitarse al estudio del ordenamiento jurídico propio, al menos si aspira a tener relevancia científica. Y lo mismo puede predicarse del legislador, que en un mundo globalizado no puede legislar en régimen de "autarquía", manteniéndose ajeno al avance legislativo de otros ordenamientos jurídicos.

Por eso, este trabajo de Langer, pese a haberse publicado por primera vez en 2004, sigue siendo hoy plenamente actual. Y encaja perfectamente en ese concepto de derecho comparado que Watson definía como el estudio de las relaciones, y principalmente las relaciones históricas entre diferentes sistemas jurídicos o entre las normas legales de más de un sistema ${ }^{2}$. Y ello a pesar de que Langer no centra su interés en el análisis de la relación histórica entre los sistemas, ni tampoco en el estudio de dos tradiciones jurídicas en abstracto. Su objetivo principal es analizar el resultado que la importación de una institución propia del sistema procesal norteamericano produce en diversos sistemas procesales receptores. Hasta llegar a ese análisis concreto que le sirve de evidencia para cuestionar el concepto de “trasplante jurídico", Langer analiza primero las características del sistema procesal adversarial frente al proceso penal de corte inquisitivo propio del derecho continental europeo ${ }^{3}$. Esa contraposición constituye la premisa necesaria para entender el significado del legal borrowing y sus efectos en el sistema procesal en el que se inserta, a través de la institución "importada" del plea bargaining.

2 Watson, A., Legal Transplants. An Approach to Comparative Law, Athens-London, The University of Georgia Press, 1993, $2^{\text {a }}$ ed., p. 9.

3 Utilizo aquí el concepto "inquisitivo" como contrapuesto al modelo angloamericano o adversarial-desvinculado de cualquier connotación ideológica-para denominar al sistema continental europeo. Dejando aquí de lado mi personal concepción de que en realidad todos los sistemas son mixtos, y de que en el sistema procesal de los Estados Unidos también hay una incoación oficial, una investigación estatal y una búsqueda de la verdad ( $\sin$ entrar a determinar qué sea la verdad en el ámbito procesal), en este trabajo uso los términos acusatorio-inquisitivo para referirme, respectivamente, al proceso de los Estados Unidos de Norteamérica y al modelo de corte continental europeo. Asumo que ello implica una simplificación terminológica, pero que en este contexto no sólo no es relevante, sino que no es el punto de discusión. Vid. al respecto, Bachmaier, L., "Acusatorio versus inquisitivo. Reflexiones acerca del proceso penal”, en Bachmaier, L. (ed.), Proceso penal y sistemas acusatorios, Madrid-Barcelona, Marcial Pons, 2008, pp. 11-48. 
Cuando, hace ya unos años, leí por primera vez este estudio de Langer, me atrapó por su lucidez, por reflejar un conocimiento cabal de los sistemas sobre los que proyecta el análisis comparado y por su agudo análisis de los mecanismos de justicia negociada. De ahí que, al recibir la invitación a reflexionar sobre el mismo, la acepté con agrado, aunque al mismo tiempo con la inquietud de que podría no hacer justicia ni al autor ni a su obra. Aun así, el entusiasmo que siento por estos temas me llevó a superar la cautela que quizás hubiera sido más prudente adoptar, y decidí asumir el reto de intentar contribuir a este debate. Debo aclarar, en todo caso, que mi objetivo no es rebatir o criticar la posición o los argumentos de la tesis que sostiene Langer, pues comparto tanto su planteamiento como su análisis, y también la conclusión a la que llega. Ni tampoco creo que sea éste el lugar para estudiar cómo ha evolucionado desde 2004 la concreta regulación de la justicia negociada en los cuatro ordenamientos jurídicos elegidos por Langer en su análisis, ni cómo deberían proyectarse a su vez esas soluciones en el sistema norteamericano ${ }^{4}$.

Lo que pretendo en estas páginas, necesariamente limitadas, es reflexionar en voz alta sobre algunas cuestiones que su lectura me ha suscitado; y lo haré más a modo de diálogo que como un análisis crítico de esta obra, entre otras razones porque poca crítica puede hacerse a un trabajo que me parece impecable. En concreto, mis reflexiones girarán en torno a la proliferación de metáforas para intentar definir esas relaciones entre sistemas jurídicos, y el encaje de la justicia negociada en una institución jurídica como es el proceso penal, cuya estructura está diseñada para lograr el esclarecimiento de unos hechos posiblemente delictivos y depurar la responsabilidad penal correspondiente. Todo ello con la modesta intención de continuar un debate académico que nos pueda guiar hacia el futuro en el campo de la justicia penal. Un futuro en el que-no es necesario insistir en ello-la ciencia jurídica inevitablemente tiene que caminar de la mano del derecho comparado en un mundo cada vez más global.

4 Posteriormente Langer sí reflexiona sobre la necesidad de reformar el sistema del plea-bargaining norteamericano en Langer, M., "Rethinking Plea Bargaining: The Practice and Reform of Prosecutorial Adjudication in American Criminal Procedure", American Journal of Criminal Law, Vol. 33, 2006, pp. 223-300. 


\section{El análisis de Langer: más allá de una re-conceptualización}

La aportación de Langer refleja un profundo conocimiento de los dos grandes sistemas procesales, el acusatorio y el inquisitivo. Pero el autor no se limita a transitar por sendas ya trilladas sino que, desde una perspectiva propia del comparatista, analiza el impacto de la implantación de fórmulas de consenso en el proceso penal de los sistemas procesales continentales europeos. Más que una comparación histórica —o de normogénesis 5 - para determinar la evolución de la influencia del modelo de justicia negociada de los Estados Unidos hacia Europa (cuándo y a través de qué cauces), se centra primordialmente en los resultados que esa transferencia ha generado. Lo que al autor le interesa es, sobre todo, el modo en que se ha recepcionado la institución del plea bargaining en el proceso penal continental europeo.

La elección del plea bargaining no es casual. Como el propio autor explicita, obedece a que se trata de una de las instituciones más características o definitorias del sistema de justicia penal norteamericano, del modelo de dispute resolution ${ }^{6}$, y que ha sido importada por un número inusitadamente alto de ordenamientos jurídicos. Esa creciente expansión resulta especialmente llamativa si se piensa que no se ha limitado a sistemas similares o próximos, sino que, a través de diversas fórmulas de consenso, la justicia negociada se ha instalado también en sistemas muy alejados en su esencia del modelo norteamericano.

Langer analiza concretamente la implantación de estas fórmulas de consenso en cuatro ordenamientos jurídicos de tradición continental europea, con el fin de valorar sus efectos y determinar si ello ha generado una "americanización" del proceso penal inquisitivo. No se limita a un examen superficial que permitiría establecer una relación causa-efecto sobre meras apariencias: es decir, concluir que, al importar instituciones propias del proceso penal USA, el proceso penal continental europeo necesariamente se ha "americanizado". El autor no se conforma con observar la punta del

5 Expresión que utiliza Wigmore, J.H., en "A New Way of Teaching Comparative Law", Journal of the SPTL, 1926, citado por Watson A., op. cit., p. 3.

6 Langer, M., "De los transplantes legales", en este número, op. cit., sección VI. 
iceberg, y se adentra en el estudio de si esa importación de instituciones ha alterado la propia concepción del proceso penal en los sistemas europeos o ha causado una mutación en cuanto a los fines que persigue.

En su análisis, Langer se detiene primero en los rasgos fundamentales de los dos modelos históricos, acusatorio e inquisitivo, pues sólo desde la previa comprensión de esos modelos-y de sus características definitorias-puede valorarse si la importación de fórmulas de consenso norteamericanas ha transformado verdaderamente el proceso inquisitivo en un proceso acusatorio.

A continuación, aboga por utilizar la metáfora de la "traducción" legal (legal translation), pues considera que ese concepto es más apropiado para definir la realidad que se observa en los procesos de exportación/importación de instituciones o normas entre ordenamientos jurídicos. Sostiene que en esa transferencia de instituciones no se produce un trasplante del elemento foráneo en el ordenamiento jurídico receptor, sino que todo ese proceso más bien podría calificarse como una traducción, pues implica necesariamente una transformación de la institución que se importa para adaptarla al contexto jurídico en el que se inserta. El legislador, al realizar un legal borrowing, no se limita a reproducir sin más la institución extranjera de que se trate, a realizar una mera operación de copia-pega, sino que, de ordinario, realiza un ajuste de la misma para encajarla en su propia política legislativa. Además, el proceso de transformación no termina ahí, y la norma o institución importada, al ajustarse al contexto en el que se aplicará, seguirá experimentando ulteriores mutaciones respecto del modelo original. Entiende que el término "traducción jurídica" refleja más adecuadamente esa circulación de ideas, de instituciones y de prácticas ${ }^{7}$.

Sobre esas bases conceptuales, Langer analiza a fondo los elementos esenciales que definen las fórmulas de consenso adoptadas en cuatro ordenamientos jurídicos representativos de la tradición jurídica continental europea, también en su versión transoceánica: Italia, Alemania, Francia y Argentina. Y su conclusión es que en ninguno de ellos la importación de soluciones de justicia negociada ha derivado en una "americanización" del proceso. Al contrario, manteniendo los rasgos esenciales del proceso 
continental, lo que ha provocado es una mayor diversidad entre ellos. La adaptación del plea bargaining al contexto procesal existente en cada uno de esos cuatro ordenamientos jurídicos no ha tenido como consecuencia que el modelo continental de proceso penal vire hacia un modelo de dispute resolution entre partes contrapuestas. Lo que se ha transformado es el instrumento de consenso para adaptarse a las estructuras de un proceso de corte más inquisitivo, en el que sigue prevaleciendo la legalidad y la búsqueda de la verdad, más que la presentación de una narrativa dual y la solución de un conflicto. Es decir, no es que la inserción de fórmulas de consenso haya alterado sustancialmente las características y principios del proceso receptor, sino que, al contrario, lo que se ha modificado es el mecanismo de plea bargaining, el cual se ha "traducido" para que pueda encajar sin demasiadas distorsiones en el modelo existente.

Para Langer, por tanto, el efecto de esa "traducción" no puede describirse propiamente como una mayor convergencia entre los sistemas de corte angloamericano y continental europeo en su respectiva concepción del proceso penal. Y al mismo tiempo, la "traducción", lejos de promover una mayor aproximación entre los sistemas receptores de las fórmulas de consenso-al haber cada uno de ellos adaptado esa institución procesal a sus propios condicionantes, objetivos y fines-ha generado una mayor diversidad entre los mismos. En esos cuatro sistemas, en el pasado, al no existir fórmulas de consenso, había uniformidad en la medida en que el único modo de resolución del conflicto discurría a través del enjuiciamiento en el juicio oral. Pero, después de la importación, aunque todos se asemejan superficialmente por el mero hecho de contar con ese nuevo sistema de conclusión del proceso penal, al elegir cada uno fórmulas diferentes han surgido importantes y visibles divergencias entre ellos.

La gran virtualidad del trabajo de Langer, más allá de la original re-conceptualización que propone, estriba en la reflexión-y constatación empírica-que realiza de esa interacción entre sistemas jurídico-procesales. Con ello nos lleva a replantear la relación entre el sistema jurídico y el contexto social que regula. Sin llegar a hablar de resistencia del sistema receptor, rechaza la metáfora del trasplante, porque considera que las importaciones jurídicas no pueden desvincularse plenamente de la transformación que el propio proceso de transferencia implica, además de los cambios que se 
generan debido a los condicionantes de realidad jurídica y social en la que se insertan.

En ese proceso de "trasplante" jurídico, el elemento trasplantado cambia su forma y su regulación; en definitiva, mutará para poder integrarse en el "cuerpo" ajeno ${ }^{8}$. Y así lo demuestra Langer con referencia a la figura del plea bargaining en el proceso penal. En el proceso de importación que ha tenido lugar en los países estudiados, se observa cómo se ha adaptado a los principios del modelo inquisitivo y a las diferentes funciones que desempeña el ministerio fiscal en un proceso en el que priman la legalidad, la certeza y la igualdad, por encima de un modelo - como el norteamericano-que hace primar la perspectiva de resolución de un conflicto, porque desconfía del rol imparcial que puedan desempeñar los representantes del Estado en el proceso penal.

\section{Trasplantes jurídicos y otras metáforas}

El debate acerca de los trasplantes jurídicos es antiguo, y no pocas veces ha llegado a cuestionarse su viabilidad. A mi juicio, puede discutirse sobre el significado de este concepto, o sobre las virtudes o deficiencias de las transferencias de soluciones jurídicas entre diferentes ordenamientos; pero no puede negarse que en la realidad los trasplantes legales han existido, existen, y probablemente seguirán existiendo?.

Como es sabido, el término lo popularizó Watson, para quien los legal transplants han sido uno de los cauces de evolución jurídica más frecuen-

8 En igual sentido, posteriormente, E. Grande, para quien resulta raro que el trasplante legal sea una "pure and straight incorporation of the foreign legal solution into the receiving system", vid. Grande, E., "Legal Transplants and the Inoculation Effect: How American Criminal Procedure has Affected Continental Europe", American Journal of Comparative Law, 64, 2016, p. 585.

9 Sin embargo, Legrand, afirma que los trasplantes legales son imposibles. Ello no significa que niegue la realidad, sino que en su crítica a Watson utiliza un concepto de norma (rule) intrínsecamente unido a su significado cultural. De ahí que "the meaning cannot be displaced, because it always refers to an idisyncratic semio-cultural situation". Vid. Legrand, P., "The impossibility of legal transplants", Maastricht Journal of Eur. \& Comp. Law, 4, issue 2, 1997, pp. 111-124, pp. 117-118. 
tes y fértiles a lo largo de la historia ${ }^{10}$. Entre otras razones para el legal borrowing, quizás la más clara es que resulta más fácil importar soluciones jurídicas que crearlas ex novo ${ }^{11}$. Watson, romanista e historiador del derecho escocés, al acuñar el término legal transplant centra parte de su estudio en la relación histórica entre sistemas y en la incidencia del derecho romano - y también del derecho canónico- en los territorios conquistados por Roma. A partir de ahí analiza, entre otros ejemplos, las causas de la penetración del derecho romano en Escocia y el mantenimiento del sistema de civil law en esa parte de lo que hoy constituye el Reino Unido. Para este autor, los massive borrowings que revela la historia contradicen la idea de Savigny de que el derecho es una expresión del espíritu de un pueblo $^{12}$. No hay duda de que existe una relación estrecha entre una sociedad y su sistema normativo, pero lo cierto es que la extensa adopción del derecho romano, y de la propia cultura romana, son clara muestra de la permeabilidad de las sociedades a sistemas jurídicos importados, nuevos y muy diferentes.

Watson estudia el trasplante de un completo sistema y a lo largo de la historia. Y, desde esa perspectiva, que podríamos denominar "macro-jurídica" y tomando como base el proceso de romanización que se extiende a través de los siglos, no es erróneo reconocer que tal transferencia no sólo es posible, sino que es históricamente constatable. Para Watson, los trasplantes jurídicos ocurridos a través de conquistas, migraciones o de procesos de importación voluntaria, como un órgano que se extrae de su cuerpo originario y se implanta en otro para desarrollar su misma función ${ }^{13}$, han sido el motor principal que ha impulsado la evolución de los ordenamientos jurídicos. Ahora bien, el propio Watson sostiene que los procesos de trasplante con frecuencia - o tal vez siempre-implican una transformación debido a que el elemento o sistema trasplantado operará

\footnotetext{
10 Watson, A., op. cit., p. 95.

11 Watson, A., op. cit., p. 21. Y cita a Roscoe Pound: "History of a system is largely a history of borrowings of legal materials from other legal systems", p. 22.

12 Idem.

13 Watson, A., op. cit., p. 27.
} 
en un contexto social diferente que lo hará funcionar de otra manera ${ }^{14}$. No hay implantación sin transformación.

En este punto, por tanto, la teoría de Langer confirma la ya expresada en su día por Watson. Ambos reconocen la realidad y la viabilidad de los trasplantes jurídicos, y la transformación que entraña ese proceso de transferencia de soluciones jurídicas de un ordenamiento a otro ${ }^{15}$. Pero, mientras que para Watson el elemento de la adaptación o mutación está implícito en el concepto de trasplante ${ }^{16}$, Langer considera que el término "traducción jurídica” es más expresivo de esa realidad. Y, si el primero aborda el trasplante desde la lógica de la historia y enfoca el trasplante como elemento de cambio de un sistema jurídico y por tanto demuestra que el derecho no es únicamente el reflejo de la sociedad en la que opera ${ }^{17}$, Langer, al centrarse en un concreto elemento del proceso penal, pone el acento más en la transformación del instituto jurídico importado para poder integrarse en el contexto procesal que lo recibe.

Personalmente, no creo que haya una contradicción entre el planteamiento de ambos autores, sino más bien una diversidad de enfoque. La perspectiva de Watson está más atenta a reafirmar la viabilidad de los trasplantes a pesar de los condicionantes del contexto social en cuestión y contradecir las teorías de Savigny del derecho como reflejo del Volksgeist; mientras que Langer incide más en la propia alteración de lo trasplantado, a través del proceso legislativo primero y de su aplicación después. Podría

${ }^{14}$ Watson, A., op. cit., p. 116: "Transplanting frequently, perhaps always, involves legal transformation. Even when the transplanted rule remains unchanged, its impact in a new social setting may be different. The insertion of an alien rule into another complex system may cause it operate in a different way".

${ }^{15}$ En contra, como Legrand, P., “The impossibility...”, op. cit., p.113, quien critica la explicación de Watson sobre la interacción entre sistemas jurídicos como de empobrecedora, porque no tiene en cuenta el verdadero significado de lo que es una norma y un sistema jurídico.

${ }^{16} \mathrm{Al}$ referirse a los legal transplants habla en términos generales de la transferencia de normas de un ordenamiento jurídico a otro, "the moving of a rule or a system of law from one country to another", $y$ alude al trasplante como un órgano que pasa a crecer en otro cuerpo y sigue viviendo como la hacía en el cuerpo originario, pero no necesariamente funcionando de manera exacta. Vid. Watson A., op. cit., pp. 21 y 27.

17 Watson, A., "The Birth of Legal Transplants", Georgia Journal of International \& Comparative Law, 41, 2003, pp. 605-608, p. 607. 
discutirse si esa diferente perspectiva justifica el cambio de terminología, pero resulta patente que ambos términos - el de trasplante jurídico en su acepción amplia y el de traducción jurídica - son válidos y reflejan una idea semejante.

Por otro lado, frente a las afirmaciones de Watson sobre la viabilidad de los trasplantes jurídicos, no son pocos los autores que han subrayado precisamente lo contrario, es decir, el fracaso del legal borrowing porque las soluciones jurídicas extranjeras no terminan de encajar en el contexto en el que se insertan, o incluso por generar fuertes resistencias frente al cambio. Así se ha expresado Teubner, quien, al estudiar el intento de armonizar a nivel europeo el principio de la buena fe contractual e implantarlo en el derecho privado inglés, se reafirma en la dificultad de trasladar instituciones jurídicas a otros ordenamientos que se asientan en principios y funcionan a través de estructuras muy diferentes ${ }^{18}$. Para este autor, esas transferencias generan rechazo en el sistema receptor y actúan como elemento "irritante"; de manera que, en lugar de llevar a una mayor armonización jurídica, generan mayores divergencias entre los sistemas que se pretenden uniformar. Concluye Teubner afirmando que de hecho la globalización no ha producido mayor armonización, sino precisamente una mayor fragmentación ${ }^{19}$. Al igual que Langer también se aparta del concepto de legal trasplants, pero no por considerarlo poco preciso, sino porque aun reconociendo que resulta sugerente, le parece que genera confusión (is in itself misleading) ${ }^{20}$.

A este propósito, conviene hacer notar que, en el contexto de los trasplantes legales, no es fácil determinar cuándo han tenido lugar con éxito o cuando han fracasado. En su estudio Langer elude esa calificación y no entra a valorar si la transformación del plea bargaining al ser introducido en otros sistemas supone un fracaso o un éxito. Y puede que esa posición sea la más razonable, pues, como señala Nelken, la definición de éxito es con-

\footnotetext{
18 Teubner G., "Legal Irritants: Good Faith in British Law or How Unifying Law Ends up in New Divergences", The Modern Law Rev., 11, 1998, pp. 11-32, pp. 12 y ss.

19 Ibidem, p. 13.

20 Ibidem, p. 12.
} 
tingente de la perspectiva que se adopte ${ }^{21}$ : apreciar el éxito de un trasplante jurídico variará en función de si se pone el foco en el sistema que exporta la norma, en la coherencia del sistema receptor, o en el cumplimiento de los fines de los actores que promueven la importación de la solución extranjera. También puede entenderse como exitoso el trasplante cuando ha habido una plena absorción de la norma jurídica en el contexto político y jurídico de destino o ha generado una equivalencia funcional. Por ello, como propone Nelken, quizás sea más oportuno hablar de los efectos del trasplante que de su éxito o fracaso. A su vez, los efectos del trasplante legal dependerán del tipo de norma o institución que se transfiere, de las características de la sociedad en la que se inserta la norma importada, y del modo o cauce en que se lleva a cabo la transmisión ${ }^{22}$. De ahí que adelantar o prever los efectos de los trasplantes jurídicos no resulte fácil en abstracto, pues son muchas las variables que determinarán el resultado.

Como he indicado, Langer elude acertadamente hablar de éxito o fracaso de la importación del plea bargaining en los sistemas de derecho continental europeo. Analiza el resultado no desde esa dicotomía, sino tomando como referencia la capacidad de transformación que esa figura, propia del sistema adversarial, ha tenido en la concepción de los procesos inquisitivos. Aunque el enfoque de Langer no coincide con la apreciación de Teubner en su trabajo sobre los legal irritants, ambos coinciden en una conclusión: que el trasplante jurídico - en Teubner más centrado en los procesos de globalización y en Langer en el plea bargaining - genera divergencias entre los diferentes ordenamientos jurídicos. Al igual que Legrand, quien reconoce que las traducciones no aspiran a dejar el original inalterado, no busca unidad, por lo que todo proceso de traducción genera divergencias ${ }^{23}$. Dicho de otro modo: la mayor interacción entre sistemas jurídicos, y el creciente

\footnotetext{
${ }^{21}$ Como señala Nelken, D. “The Meaning of Success in Transnational Legal Transfers", Windsor Yearbook of Access to Justice, 19, 2001, pp. 349-366, pp. 350 y ss.

22 Ibidem, p. 354.

23 "Translation acts as an operator of difference; it has a difference-creating power", vid. Legrand, P., "The same and the different", en Legrand, P. y Munday, R. (eds.), Comparative Legal Studies: Traditions and Transitions, Cambridge University Press, Cambridge, 2003, pp. 240-311, p. 291.
} 
La no-americanización del proceso penal continental europeo

número de transferencias e influencias mutuas, no han dado lugar a una mayor uniformidad sino todo lo contrario ${ }^{24}$.

Los comparatistas parecen tener un gusto especial por el recurso a las metáforas, quizás porque, después de más de un siglo, el concepto de derecho comparado sigue moviéndose en unos contornos poco nítidos. Una metáfora se define como una figura retórica de pensamiento por medio de la cual una realidad o concepto se expresan a través de una realidad o concepto diferentes con los que lo representado guarda cierta relación de semejanza. Recurrir a las metáforas implica una suerte de etiquetación de un fenómeno y cumple una función cognitiva: permite un mejor conocimiento y una comunicación más expresiva, al utilizarse términos propios de un ámbito conceptual en otro contexto receptor.

En el ámbito jurídico, si bien no se utilizan con la frecuencia que aparecen en el discurso político, en el derecho comparado sí han proliferado las metáforas para definir el tipo de relación que se produce entre sistemas jurídicos y los efectos que tales relaciones generan en el sistema receptor. Así, encontramos en la literatura jurídica, entre otros, términos como legal transplants ${ }^{25}$, legal irritants ${ }^{26}$, legal formant ${ }^{27}$, legal resistant ${ }^{28}$, legal inocu-

${ }^{24}$ Sin embargo, sí considera que existe convergencia entre los sistemas de civil y common law, Merryman, J.H., "On the Convergence (and Divergence) of the Civil Law and the Common Law", en The Loneliness of the Comparative Lawyer. And Other Essays in Foreign and Comparative Law, Kluwer Law Intl, The Hague, 1999, pp. 17-52, pp. 28-29, originariamente publicado en 1978 en New Perspectives for Common Law in Europe, M. Cappelletti (ed.). También para Pérez-Perdomo R. y Friedman M., la convergencia entre sistemas está cada vez más presente, "Latin Legal Cultures in the Age of Globalization", en Friedman M. y Pérez-Perdomo R. (eds.), Legal Culture in the Age of Globalization. Latin America and Latin Europe, Stanford University Press, Stanford, 2003, pp. 1-19, p. 17.

25 Watson, A., Legal Transplants..., op. cit.

26 Teubner, G., "Legal Irritants: ..., op. cit. pp. 11-32.

27 Sacco, R., "Legal formants: a Dynamic Approach to Comparative Law, American Journal of Comparative Law, 39, 1991, pp. 1343 y ss.; Watson, A., "From Legal Transplants to Legal Formants", American Journal of Comparative Law, 43, 1995, pp. 469-476.

${ }^{28}$ Jackson, J.D., "Playing the Culture Card in Resisting Cross-Jurisdictional Transplants: A Comment on Legal Processes and National Culture”, Cardozo Journal of Intl. \& Comp. Law, 5,1997 , pp. 51 y ss. 
lation $^{29}$, legal contaminations ${ }^{30}$; y, en su trabajo, como hemos visto, Langer propone el término legal translations ${ }^{31}$.

Ante esa variedad terminológica cabe preguntarse: ¿cumplen estas metáforas la función cognitiva que en teoría persiguen? ¿Cuál es la razón para que diferentes autores recurran a nuevas metáforas para describir el fenómeno de los trasplantes jurídicos? ¿Qué término describe mejor los resultados de la interacción entre sistemas jurídicos, y los efectos de la importación/exportación de soluciones legislativas? ¿Hay confusión entre todas ellas o se trata de un afán por crear un concepto -o simplemente un término- más original que el precedente?

Sin entrar a analizar en detalle cada uno de los términos anteriores, no parece que ninguno sea más preciso que otro, o más correcto que otro, pues en realidad cada uno describe realidades diferentes en cuanto a la interacción entre sistemas o al impacto de la importación de soluciones jurídicas de otros ordenamientos. Además, esa multitud de metáforas puede verse también como una consecuencia de la diversidad de enfoques que admite el estudio del derecho comparado ${ }^{32}$. Y, en fin, ponen de relieve que existen diferentes tipos de transferencias jurídicas, que pueden obedecer a circunstancias internas o externas, y que, dependiendo del ámbito sobre el que se proyectan, se asimilarán fácilmente o, por el contrario, generarán distorsiones y resistencias en el ordenamiento jurídico receptor. A su vez, una tal resistencia puede tener causas muy variadas y, según Teubner ${ }^{33}$, dependerá del grado en que la norma o institución jurídica que se pretende implantar esté conectada con los elementos integradores de esa sociedad. De ahí que en determinadas áreas jurídicas el trasplante será tarea fácil,

${ }^{29}$ Grande, E., op. cit., pp. 583-618.

${ }^{30}$ Monateri, P. G., "The 'Weak Law': Contaminations and Legal Cultures. Borrowing of Legal and Political Forms”, Transnat'l L. \& Contemp. Probs., 13, 2003, pp. 575 y ss., accesible en www.alanwatson.org.

${ }^{31}$ Esta enumeración de metáforas puede completarse con la que incluye E. Grande, op. cit., p. 585, en la que menciona: legal fluxes, legal grafts, legal circulation o legal migration.

33 Teubner, G., op. cit., pp.18-21. 
La no-americanización del proceso penal continental europeo

mientras que en otras áreas, más intrínsecamente unidas al contexto social, se dará mayor resistencia frente a lo foráneo ${ }^{34}$.

\section{De la traducción legal a la inoculación legal}

La metáfora a la que recurre Langer resulta muy ilustrativa para definir el proceso de importación del plea bargaining en los sistemas de derecho continental europeo. El concepto de traducción tiene diversas acepciones, desde la más literal ("expresar en un idioma lo dicho o escrito originariamente en otro distinto") hasta la más amplia ("convertir o transformar una cosa en otra"), pasando por otra intermedia ("explicar o expresar de forma diferente algo que ya se ha expresado de otra forma") ${ }^{35}$. Dentro de la teoría de la traducción jurídica se reflejan esos distintos enfoques, en una evolución desde la traducción literal, como la que exigió el emperador Justiniano para la traducción del Corpus Iuris Civilis, hasta la aceptación en el siglo XX de la traducción idiomática ${ }^{36}$. En el estudio de Langer sobre la adopción de formas de consenso en diversos ordenamientos jurídicos europeos, resulta visible que utiliza el término traducción en un sentido más amplio, al analizar cómo la institución americana pasa a "expresarse de otra forma" al ser legislada y aplicada en esos cuatro ordenamientos jurídicos. El concepto de interpretación es consustancial a toda traducción; y toda traducción implica un proceso de "decodificación" para adaptar el término original al contexto donde se ha de insertar el término traducido ${ }^{37}$. En definitiva, el término elegido por Langer no puede ser más acertado.

34 Teubner, G., op. cit., p. 19: "While in loosely coupled areas of law a tranfer is comparably easy to accomplish, the resistance to change is high when law is tightly coupled in binding arangements to other social processes".

35 Diccionario General de la Lengua Española Vox.

${ }^{36}$ Sarcevic, S., New Approach to Legal Translation, The Hague, London, Kluwer Law Intl., 1997, pp. 24-36. A lo largo de la historia de la traducción jurídica, según esta autora, el debate entre hacer primar en la traducción la letra o el espíritu del texto a traducir, ha sido continuo, pp. 36-37.

37 Vid. Grosswald Curran, V., "Comparative Law and Language", en Reinmann, M. y Zimmermann, R. (eds.), The Oxford Handbook of Comparative Law, Oxford U.P., Oxford, 2006, pp. 675-707, p. 677. 
Pero el símil de la traducción no es sólo adecuado para definir las relaciones que se producen en el proceso de legal borrowing, sino también para la propia comprensión de lo que es en sí el derecho comparado. Si la transmisión de soluciones jurídicas de un ordenamiento jurídico a otro puede entenderse como un proceso de traducción, la propia comparación entre los sistemas actúa asimismo como lo haría la traducción entre dos lenguas diferentes. El traductor, a través de la interpretación del original y su reconstrucción, busca y elabora el significado de un término. De igual manera, el comparatista, al adentrarse en un ordenamiento jurídico extranjero, también tratará de "traducir" esas normas o instituciones extranjeras para entender su significado: traduce el sentido jurídico de esa institución para comprender su funcionamiento y así hacer posible la comunicación entre sistemas. Y en ese proceso, no sólo aprende una lengua-sistema nuevo, sino que ahonda en la comprensión del propio ${ }^{38}$. El derecho comparado, al igual que la traducción, nos permite adentrarnos en otras "lenguas", comprender otras realidades y así, con esa visión más amplia, entender mejor lo propio.

Langer es muy consciente de esa conexión entre lenguaje y derecho comparado, y eso es quizás lo que le permite captar la utilidad del término "traducción" para definir lo que ha sucedido al introducir fórmulas de consenso del proceso norteamericano en el proceso continental europeo. $\mathrm{Y}$ advierte que en ese proceso no se llegan a modificar las estructuras fundamentales del proceso inquisitivo, sino que, al contrario, es el plea bargaining el que experimenta una transformación, una traducción, que lo hace comprensible y compatible con el sistema en el que se inserta, sin alterar este sustancialmente.

Posteriormente, Grande, retomando las ideas de Langer, avanza aún más en su apreciación del resultado de la importación de elementos del proceso norteamericano en el proceso continental. Coincide con Langer en que la adopción de elementos propios del sistema americano no ha

${ }^{38}$ Grosswald, V., op. cit., p. 699: "If comparative law is the translator of the law of others and otherness, but translation is not the making equivalent of foreign languages, only a lantern that makes visible how every mode of meaning signifies". 
La no-americanización del proceso penal continental europeo

producido una americanización del proceso penal continental europeo ${ }^{39}$, pues no se ha transformado en un proceso entre verdaderas partes (party-driven) que defienden intereses propios, ni el tribunal permanece ajeno a la finalidad de esclarecimiento de la verdad ${ }^{40}$. Pero esta autora va más allá al constatar - a mi juicio de forma convincente- que ese proceso que a primera vista podría parecer de convergencia entre sistemas, en lugar de una americanización del proceso continental, ha provocado el efecto contrario: es decir, que el proceso penal europeo se ha "inmunizado" frente a la influencia norteamericana. Considera Grande que la importación de elementos característicos de sistemas adversariales —entre ellos las fórmulas de consenso- han actuado como una vacuna en los sistemas receptores. Así, la introducción de un elemento extraño como es el plea bargaining, junto a otros elementos propios del proceso USA, han venido a reforzar una de las características más salientes del proceso continental: la instrucción penal en manos de un funcionario público que de forma imparcial actúa en busca de la verdad en relación con los hechos delictivos ${ }^{41}$.

En el ámbito de la justicia penal, el sistema continental ha acogido lo que resultaba útil para la gestión más eficaz de sus procesos en forma de fórmulas de consenso, pero sin renunciar a preservar el principio de igualdad, la seguridad jurídica y la imparcialidad en la instrucción. Sigue apostando por la necesidad de dotar a un órgano público con imparcialidad para que investigue los hechos de la manera más exhaustiva posible, con el único fin de hallar la verdad histórica, o de aproximarse a ella. Para contrarrestar la posible parcialidad de esa reconstrucción oficial de los hechos, así como en el ejercicio de la acción penal, el sistema continental en muchos ordenamientos jurídicos da entrada a otros actores en el proceso, como

${ }^{39}$ La conclusión es la misma, aunque el trabajo de Langer se centra en la institución del plea bargaining, mientras que Grande alude no sólo a esta institución, sino también al jurado, las reglas de exclusión de prueba, la contradicción de la prueba y, fundamentalmente, el rol del ministerio público, a la hora de fundar su argumento de la inmunización frente a la americanización.

40 En contra de considerar que toda iniciativa probatoria del tribunal enjuiciador conlleva una pérdida de la imparcialidad judicial, vid. Bachmaier, L., "Imparcialidad y prueba en el proceso penal: reflexiones sobre la iniciativa probatoria", Rev. Brasileira de Direito Processual Penal, vol. 4/2, mayo/agosto 2018, pp. 501-532.

${ }^{41}$ Grande, E., op. cit., p. 583. 
es el caso de la víctima y otros sujetos legitimados para defender el interés de la sociedad. Sobre esa investigación oficial neutral se asienta en el ámbito continental la concepción de un enjuiciamiento penal justo. Por tanto, según Grande, la introducción de elementos del proceso penal USA no ha supuesto un trasplante completo, ni tampoco se reduce a una mera traducción legislativa: el efecto ha sido el de una verdadera inmunización de los sistemas continentales frente a la eventual adopción de un genuino proceso adversarial en el futuro ${ }^{42}$.

Al igual que Langer, Grande reconoce que toda importación jurídica implica una adaptación al contexto en el que se inserta, algo que expresó muy gráficamente Damaska, indicando que la música "legal" suena diferente cuando cambian los músicos y los instrumentos ${ }^{43}$. Yo añadiría aun, que a veces esa "adaptación" produce una completa distorsión, una música completamente desafinada, como ha sido el caso de la importación del plea-bargaining en democracias en transición ${ }^{44}$.

En el caso del proceso penal, la influencia norteamericana no ha logrado que el sistema continental abandone su rasgo probablemente más definitorio, como es la inquisitio o instrucción oficial, sino que la ha visto reforzada. Esta idea está también presente en el trabajo de Langer, pues el proceso de "traducción" legal implica una adaptación a la estructura inquisitiva existente, $\mathrm{y}$ al reconocer que tales estructuras y principios no han mutado, está visualizando la resistencia del modelo continental frente al norteamericano. Si entendemos que la resistencia del sistema inquisitivo frente a la americanización, a su vez, implica un reforzamiento del proceso penal continental europeo, entonces sí puede compartirse la idea de que esos elementos ajenos han generado una inmunización a través de inoculación. En ese sentido, en el trabajo de Langer ya está implícita la idea de

42 Grande, E., op. cit., p. 584.

43 Damaska, M.,"The Uncertain Fate of Evidentiary Transplants: Anglo-American and Continental Experiments", American Journal of Comparative Law, 45, 1997, pp. 839-852, p. 840: "The music of the law changes, so to speak, when the musical instruments and the players are no longer the same".

44 Vid. al respecto Bachmaier, L., “The European Court of Human Right's Confronted with Negotiated Justice and Coercion", European Journal of Crime, Criminal Law and Criminal Justice, 26, 2018, pp. 236-259, en relación con el sistema implantado en Georgia. 
La no-americanización del proceso penal continental europeo

resistencia, de manera que el trabajo de Grande vendría a confirmar su análisis, aunque añadiendo una nueva metáfora igualmente original.

\section{Sistema inquisitivo, justicia negociada, y verdad en el proceso penal}

Se pregunta Langer cómo diferenciar, tanto en el sistema inquisitivo como en el adversarial, entre los elementos principales y aquellos otros que son secundarios o no definitorios ${ }^{45}$. Y sugiere como elementos clave del modelo inquisitivo los siguientes: la búsqueda de la verdad, la no disposición de la acción penal, la investigación unitaria y exhaustiva de los hechos, y por ende, la prevalencia del modelo de investigación oficial frente al modelo de disputa.

No es desde luego fácil definir estos dos modelos conceptuales (que no históricos, pues históricamente también presentaban muchas modalidades como sistemas mixtos). No obstante, desde mi punto de vista, quizás pueda considerarse que el objetivo de lograr la reconstrucción unitaria e imparcial de los hechos es el rasgo más claramente definitorio de los sistemas inquisitivos, mientras que la elaboración de una narrativa dual por partes enfrentadas sería el más característico del sistema acusatorio norteamericano.

Un segundo rasgo definitorio del proceso típico continental consistiría en que, como colofón de la investigación oficial e imparcial, las diligencias practicadas en la fase de instrucción podrían adquirir mayor valor probatorio o al menos no se les aplica con tanta rigidez la regla de exclusión del hearsay ${ }^{46}$, como sucede en el norteamericano. En tercer lugar, podemos mencionar una concepción diferente de la seguridad jurídica y del principio de igualdad en la aplicación de la sanción penal en cada modelo. Lo cual permite que en el sistema norteamericano la acusación tenga un mayor poder discrecional en el ejercicio de la acción penal, frente a la prevalencia del principio de legalidad en los sistemas continentales - si bien ahora atenuada en muchos procesos inquisitivos mediante la denominada

${ }^{45}$ Langer, M., en este volumen, op. cit., sección III.

${ }^{46}$ Artículo 801 de las Federal Rules of Evidence. 
oportunidad reglada - . El cuarto elemento que creo determinante para diferenciar estos dos modelos es el institucional: tanto el diverso papel que desempeña la fiscalía ${ }^{47}$, como la composición del tribunal enjuiciador.

A pesar de esas notas diferenciadoras - como mera síntesis y sin ánimo de exhaustividad - no debe olvidarse que ninguno de los sistemas en su configuración actual ha sido inmune a la influencia mutua, y de ahí que los modelos sólo tengan actualmente un significado conceptual, pues en el presente sólo encontramos procesos mixtos. Así, todo sistema penal contemporáneo que pudiéramos denominar adversarial presenta un rasgo esencial del modelo inquisitivo, que es la investigación del delito como responsabilidad pública, que corresponde al Estado en tanto que garante de la seguridad de los ciudadanos ${ }^{48}$.

La incoación de una investigación de oficio es un rasgo netamente inquisitivo que se encuentra presente tanto en los procesos encuadrables dentro del modelo adversarial como en aquellos que pertenecen al modelo continental europeo. Como ya señalé anteriormente ${ }^{49}$, el proceso inquisitivo convirtió la instrucción penal — que debía basarse en la búsqueda de la verdad - en una cuestión pública ${ }^{50}$. De tal manera que, ante un hecho delictivo, o más precisamente ante la notitia criminis, debía incoarse de oficio la investigación penal. Esto sucede en todo sistema de justicia penal evolucionado: un Estado moderno pone en marcha de oficio la maquinaria

${ }^{47}$ En igual sentido Langer M., op. cit., sección VI. Sobre el rol del ministerio fiscal en el sistema de justicia de los Estados Unidos, vid. el interesante trabajo de Sklansky, D., "Unpacking the Relationship between Prosecutors and Democracy in the United States", en Langer, M. y Sklansky, D., (eds.), Prosecutors and Democracy. A Cross-national Study, Cambridge, Cambridge University Press, 2017, pp. 276-299, poniendo de relieve cómo es una institución a camino entre el poder ejecutivo y judicial, con un perfil político único en el panorama comparado y que ningún otro ordenamiento jurídico consideraría apto para ser importado, p. 277.

48 Vid. al respecto Bachmaier, L., "Acusatorio versus inqusitivo..., op. cit., pp. 30-31; Jung, H., "Anmerkungen zum Verhältnis von Strafe und Staat", Goltdammer's Archiv für Strafrecht, 1996, pp. 507 y ss.

49 Bachmaier, L., "Acusatorio versus inquisitivo..., op. cit., p. 47.

${ }^{50}$ Langbein, J.H., The origins of adversary criminal trial, Oxford University Press, Oxford, 2003, p. 342. 
estatal de investigación del hecho delictivo ante la existencia de indicios ${ }^{51}$. Lo mismo puede decirse de la doble instancia penal, que fue una aportación propia del modelo inquisitivo y se halla extendida en la actualidad como garantía fundamental en cualquier sistema de justicia criminal. A su vez, hace ya mucho tiempo que los sistemas basados en el modelo inquisitivo apostaron por dar protagonismo al juicio oral contradictorio, mediante reglas que reducen el valor probatorio de lo actuado en la fase de instrucción. En suma, puede con rigor afirmarse que todos los sistemas actuales son mixtos, en la medida en que presentan elementos conceptualmente pertenecientes a los dos modelos de proceso penal.

Ahora bien, tradicionalmente se asume que en el proceso adversarial prima una concepción del proceso cuyo fin es la resolución del conflicto frente a la averiguación de la verdad. Y a su vez se considera que una tal concepción ha facilitado la aplicación extensiva del plea bargaining como mecanismo que encaja en la dinámica de resolución de conflicto por encima del objetivo de hacer justicia, del principio de legalidad y de la igualdad en la aplicación de la sanción penal. Correlativamente, se argumenta que en los sistemas continentales la búsqueda de la verdad como fin del proceso impediría aplicar una resolución negociada. Y lo cierto es que ninguna objeción sustancial puede hacerse a esta caracterización, por simplificada que sea.

Lo que no me parece tan asumible, en cambio, es entender que el proceso norteamericano, definido como de partes (party-driven) y que confiere mayor relevancia a la dispute resolution, prescinda plenamente del objetivo de la búsqueda de la verdad.

A este propósito, resulta patente que la reconstrucción de unos hechos determinados, y el desarrollo de una narrativa acerca de cómo ocurrieron los mismos (a truth narrative), constituyen la premisa para aplicar una sanción penal que pueda considerarse justa ${ }^{52}$. Aproximarse a la verdad his-

${ }^{51}$ El sistema de control sobre el inicio de la investigación penal variará en cada sistema. La presencia de un órgano independiente e imparcial en la fase - ya sea el grand jury o un juez- es una garantía adicional para el ciudadano frente al poder del Estado en el uso de técnicas de control e investigación de los ciudadanos.

52 Así también, Gössel, K.H., "Ermittlung oder Herstellung von Wahrheit im Strafprozess?: Vortrag gehalten vor der Juristischen Gesellschaft zu Berlin am 2.6.1999", Schriftenreihe der 
tórica es el objetivo de la práctica de la prueba; el proceso no determina la verdad de los hechos, sino que está estructurado para averiguar esa verdad (aunque ese objetivo no siempre sea alcanzado) ${ }^{53}$. Sin entrar aquí en complejas cuestiones filosóficas acerca del concepto de verdad, y admitiendo que la verdad como tal no es un fin que pueda lograrse por completo en el proceso penal ${ }^{54}$, parto del convencimiento de que el proceso penal ha de estar concebido y diseñado de modo que pueda facilitar el mayor acercamiento posible a la realidad histórica de los hechos, una verdad contingente que no absoluta ${ }^{55}$, siempre dentro del marco del respeto de los derechos fundamentales de las personas y de las garantías procesales.

Cuestión diversa es cuál se considera que es el mejor camino para llegar a esa verdad: si a través de una investigación oficial exhaustiva de todos los hechos y la presentación de un relato único; o bien confiriendo poderes a cada una de las partes para que aporte los hechos y medios de prueba que fundamentan su posición, estableciendo un relato dual contrapuesto. Por ello, al margen de las diversas concepciones del proceso que subyacen a cada uno de esos modelos, lo cierto es que ambos parten del mismo postulado esencial: el juicio ha de ser el resultado de la valoración de pruebas legales y fiables que permitan conocer, en lo posible, la realidad de los hechos sobre los que ha de fundamentarse el fallo. $\mathrm{Y}$ en ambos modelos, puede prescindirse del juicio, si el acusado renuncia voluntariamente a su derecho al mismo, y existe una base fáctica suficiente que sostenga la acusación.

Se puede discutir cuál de los dos sistemas, el norteamericano o el continental, es más adecuado por lo que se refiere a la completa aportación de pruebas y la presentación de los hechos. Pero resulta indiscutible que llegados a juicio cada uno de ellos busca hallar la verdad, aunque sea por

Juristischen Gesellschaft zu Berlin 165, Berlin, 2000, pp. 5-20, p. 19.

${ }^{53}$ Por todos, vid. Guzmán, N., La verdad en el proceso penal. Una contribución a la epistemología jurídica, Buenos Aires, Ed. El Puerto, 2006, pp. 150 y ss., donde analiza en profundidad las diversas concepciones de la verdad, los límites del proceso y, también el contradictorio como método para el conocimiento de esa verdad.

${ }^{54}$ Guzmán, N., op. cit., p. 19 y ss.

55 Coincido aquí plenamente con Damaska, M., "Truth in Adjudication”, Hasting Law Journal, 49, 1998, pp. 289 y ss.; Langer, M., “In the Beginning...”, op. cit., pp. 277-278, pp. 300-301. 
un camino diferente, y quizá poniendo el acento de manera distinta en este aspecto $^{56}$. Pero sería irreal sostener que el proceso penal norteamericano prescinde completamente del objetivo de búsqueda de la verdad. Sucede que adopta como punto de partida que es imposible que la investigación de un órgano público pueda ser lo suficientemente imparcial como para llegar a cumplir ese objetivo ${ }^{57}$. Por eso, opta por la contraposición de las versiones de las partes enfrentadas - acusación y acusado- como mecanismo para esclarecer los hechos. Esa confrontación es la que permitirá, si no establecer la verdad, al menos aproximarse a ella de manera más fiable que a través de un órgano estatal, de cuya imparcialidad el sistema norteamericano desconfía casi instintivamente.

Que se conciba el proceso como trasunto entre las partes, y por tanto que se deje en sus manos la consecución del interés público, no significa que la estructura del proceso no persiga fijar unos hechos conforme a la verdad histórica como paso previo y necesario para emitir un juicio. Lo contrario, como ya he indicado, no sólo sería inaceptable desde la más elemental concepción de la justicia, sino que sería también incoherente con el diseño y las facultades de averiguación de los hechos articuladas en el proceso civil a través del discovery. ¿Alguien entendería que el proceso de las Federal Rules of Civil Procedure se configure como una estructura que permita el pleno esclarecimiento de los hechos conforme a la verdad, y sin embargo en el proceso penal se prescindiera de ese mismo objetivo? La respuesta cae por sí sola.

Partiendo entonces de que en ambos sistemas el proceso debe servir para averiguar la verdad - si bien con diversa intensidad - lo cierto es que a la hora de aceptar el plea bargaining, sí se aprecian en el sistema USA importantes concesiones a la verdad, sobre todo a la vista de la denominada Alford $\mathrm{plea}^{58}$.

${ }^{56}$ Damaska M., “Truth in Adjudication”, op. cit., pp. 289 y ss.; Langer, M., "In the Beginning...”, op. cit., pp. 277-278; Weigend, T., "Should We Search for the Truth, and Who Should Do It?", North Carolina Journal of International Law \& Commercial Regulation, 36, 2011, pp. 389 y ss.

57 Grande, E., op. cit., p. 589.

${ }^{58}$ United States $v$. Alford, 400 U.S. 25, 1970, aceptando el guilty plea y al mismo tiempo la declaración de inocencia del acusado. 
Además, la amplitud de la discrecionalidad en el ejercicio de la acción penal y, por tanto, el enfoque del proceso penal como mecanismo para resolver un conflicto entre partes, frente al rígido sometimiento al principio de legalidad, sitúa el esclarecimiento de los hechos claramente en una posición menos destacada que en el proceso europeo. El mayor margen de discrecionalidad que hay en el modelo norteamericano en relación con la justicia negociada es resultado de esa función primordial que se entiende ha de cumplir el proceso, y también de la diferente legitimidad del ministerio fiscal. El modelo USA no concibe que un órgano oficial pueda actuar de forma plenamente imparcial al servicio de la averiguación de unos hechos $^{59}$, o bien prefiere no dotar al ministerio fiscal de esa función para prevenir abusos del poder estatal. Opta por un modelo de coordinación frente al modelo jerárquico continental.

Pero el modelo continental comparte hasta cierto punto esa desconfianza, y por ello tradicionalmente ha limitado el poder discrecional de la fiscalía, tanto a la hora de decidir sobre la acción penal como en el proceso negociador con el acusado. El principio de legalidad actúa así como límite a los poderes discrecionales del ministerio fiscal, como garante de la igualdad - que todo acto y persona van a ser perseguidos conforme a los mismos criterios legales - y también como elemento que legitima la actuación del fiscal.

El plea bargaining o los plea agreements no chocan necesariamente con la concepción del proceso como instrumento para establecer unos hechos - conforme a la verdad o meta-verdad - que a su vez son la premisa para determinar una responsabilidad penal. Sobre todo cuando las fórmulas de consenso no alteran el desarrollo de la fase de instrucción. Lo que resulta más difícilmente encajable en el sistema continental europeo es la posibilidad de disponer de la acusación conforme a criterios discrecionales y la negociación de la acusación y/o la pena por parte del ministerio fiscal. Esa mayor discrecionalidad a la hora de alcanzar una conformidad sí plantea contradicciones con el principio de legalidad y la igualdad, con la seguridad jurídica y con el rol tradicionalmente asignado al ministerio fiscal como sujeto que sólo es parte formal en el proceso penal. 
Es ahí precisamente donde entra en acción el proceso de traducción legal que tan bien define e identifica Langer, para conseguir que los principios sobre los que se asienta el proceso penal continental y todo el juego de contrapesos institucionales no se vean sacrificados a través de un sistema de condenas sin juicio, ya sean negociadas o aceptadas.

¿Implica esa importación del plea bargaining una americanización del proceso penal continental europeo? Como Langer pone de relieve, la importación de fórmulas de consenso en Europa puede calificarse como una americanización "débil", en la medida en que el sistema continental se ha abierto a cierta flexibilización del principio de igualdad - por razón de eficiencia en la resolución del conflicto- dando paso a ciertas manifestaciones del principio de oportunidad. Pero ello no ha llevado a alterar la estructura básica del proceso penal, que continúa asentada sobre una investigación exhaustiva de los hechos presidida por la imparcialidad, por parte de un órgano oficial que actúa únicamente guiado por la defensa de la legalidad.

¿Puede calificarse esa importación de positiva? Desde la perspectiva de la eficiencia, sin lugar a dudas. Y quizás ese haya sido el motivo principal por el cual las fórmulas de consenso se hayan expandido de manera exponencial en el ámbito europeo. Por otro lado, si esa importación se valora desde la perspectiva de los derechos fundamentales y las garantías procesales del acusado, tampoco puede calificarse de negativa, pues no se han detectado graves vulneraciones en el ámbito europeo (no puedo pronunciarme acerca del proceso penal argentino). Y, desde el punto de vista de la coherencia del sistema, si entendemos rigurosamente que un proceso justo es sólo aquel que lleva a la determinación de la verdad a través de la celebración del juicio con plena inmediación en la práctica de la prueba, puede resultar difícil admitir un mecanismo de justicia negociada que prescinda del elemento esencial del proceso, que es el juicio. Pero únicamente desde esa limitada óptica resultaría la justicia negociada incoherente con el sistema continental europeo. Obviamente, lo que no resulta posible es valorar si este trasplante o traducción jurídica ha sido el cauce más efectivo para desarrollar los sistemas en los que se han insertado fórmulas de consenso, pues en las reformas jurídicas carecemos de laboratorio para medir el efecto de soluciones alternativas ${ }^{60}$.

${ }^{60}$ Así también, Merryman, J.H., op. cit., p. 30. 
Por otro lado, cuando observamos la introducción de fórmulas de consenso en un modelo procesal basado en una investigación oficial imparcial dirigida a la búsqueda de la verdad y la tutela de la legalidad, comprobamos que no sólo no ha generado graves incoherencias, sino que no se han detectado graves patologías en forma de prácticas coercitivas como las que han podido darse con el sistema de plea bargaining en los Estados Unidos. La existencia de un ministerio fiscal imparcial cuya función es defender la legalidad, unida a una serie de razonables limitaciones en su poder discrecional, ha contribuido a evitar que la justicia negociada adquiera en los países europeos rasgos coercitivos.

\section{A modo de conclusión}

Para Langer, "traducción jurídica" es un concepto más apropiado que "trasplante jurídico" para definir el proceso de importación del plea bargaining por parte de diversos ordenamientos jurídicos que siguen el modelo continental europeo de justicia penal. El análisis es acertado y la metáfora es expresiva, si bien, a mi juicio, el término legal translation no anula la validez del más genérico legal transplant, pues no considero que este último carezca de la flexibilidad que Langer le atribuye ${ }^{61}$.

Quizás el siguiente paso sea poner de relieve cómo a veces el resultado de la traducción legal no sólo genera una diversificación en los ordenamientos jurídicos importadores, sino también una mejora respecto del instrumento legal original que se importa. Al integrarse en el sistema continental, el plea bargaining norteamericano ha cambiado, y creo que a mejor. Tal vez algunos vean en esa mutación un fracaso del trasplante, pero, como ya se ha expuesto antes, todo depende del enfoque que se adopte ante los términos fracaso o éxito. Lo que sí puede afirmarse es que la inserción de fórmulas de consenso en el proceso penal de corte continental ha contribuido a dotarlo de mayor eficiencia, canalizando también las demandas de una sociedad que reclama

${ }^{61}$ Langer, M., op. cit., sección V: "la metáfora del trasplante no es lo suficientemente flexible para captar estos matices”, refiriéndose a que sirve para explicitar los trasplantes que se producen a ciertos niveles conceptuales, pero no a todos los niveles. 
respuestas más eficaces y rápidas frente el delito. Si eso se ha logrado sin quebrar las aspiraciones de esas sociedades a vivir en un marco democrático, seguro y con pleno cumplimiento de sus derechos fundamentales, yo veo difícil calificar esta importación de otra forma que no sea como éxito.

En el caso de la justicia negociada, podría hablarse quizás también de una especie de reactivación de fórmulas de consenso que existieron históricamente en los procesos acusatorios europeos en los que era frecuente que las partes - dueñas del proceso- negociaran el perdón a cambio del resarcimiento del daño. Quién importa o exporta primero la institución y el modelo acusatorio no es objeto de este debate, pero sí quería mencionar esta interacción histórica entre el proceso romano y el proceso del common law. Sea como fuere, coincido plenamente con Langer en que la importación del plea-bargaining no ha producido una americanización del proceso penal europeo, porque su concepción estructural, sus bases más profundas, no se han visto alteradas.

Una cuestión interesante para el derecho comparado es la relativa a las razones por las que los sistemas continental-europeos han importado algunas instituciones procesales norteamericanas, pero lo mismo no ha sucedido a la inversa: el derecho procesal norteamericano se muestra resistente a recibir cualquier aportación proveniente del modelo continental europeo. Parece como si, en esta materia, transitáramos por una avenida de una sola dirección ${ }^{62}$. No está de más llamar la atención sobre esta realidad, que quizás podríamos describir mediante el recurso a otra metáfora: impermeabilidad o enrocamiento legal de algunos sistemas frente a cualquier importación foránea. Y esa impermeabilidad ¿cómo habríamos de calificarla, de éxito o de fracaso?

${ }^{62}$ Como ya lo puso de manifiesto Langbein hace ya dos décadas. Langbein, J. H., "The Influence of Comparative Procedure in the United States", American Journal of Compara- 


\section{Bibliografía}

Ambos, K., "El principio acusatorio y el proceso acusatorio: un intento de comprender su significado actual desde la perspectiva histórica", en Bachmaier, L. (ed.), Proceso penal y sistemas acusatorios, MadridBarcelona, Marcial Pons, 2008, pp. 49-72.

Bachmaier, L., "Acusatorio versus inquisitivo. Reflexiones acerca del proceso penal", en Bachmaier, L. (ed.), Proceso penal y sistemas acusatorios, Madrid-Barcelona, Marcial Pons, 2008, pp. 11-48.

Bachmaier, L., "Imparcialidad y prueba en el proceso penal: reflexiones sobre la iniciativa probatoria", Rev. Brasileira de Direito Processual Penal, vol. 4/2, mayo/agosto 2018, pp. 501-532.

Bachmaier, L., “The European Court of Human Right's Confronted with Negotiated Justice and Coercion", European Journal of Crime, Criminal Law and Criminal Justice, 26, 2018, pp. 236-259.

Damaska, M., “The Uncertain Fate of Evidentiary Transplants: AngloAmerican and Continental Experiments", American Journal of Comparative Law, 45, 1997, pp. 839-852.

Damaska, M., "Truth in Adjudication”, Hasting Law Journal, 49, 1998, pp. 289-308.

Gössel, K.H., “Ermittlung oder Herstellung von Wahrheit im Strafprozess?: Vortrag gehalten vor der Juristischen Gesellschaft zu Berlin am 2. Juni 1999", Schriftenreihe der Juristischen Gesellschaft zu Berlin, Berlin, Heft165, 2000, pp. 5-20.

Grande, E., "Legal Transplants and the Inoculation Effect: How American Criminal Procedure has Affected Continental Europe", American Journal of Comparative Law, 64, 2016, pp. 583-618.

Grosswald Curran, V., “Comparative Law and Language”, en Reinmann M. y Zimmermann R. (eds.), The Oxford Handbook of Comparative Law, Oxford, Oxford U.P., 2006, pp. 675-707.

Guzmán, N., La verdad en el proceso penal. Una contribución a la epistemología jurídica, Buenos Aires, Del Puerto, 2006. 
Jackson, J.D., "Playing the Culture Card in Resisting Cross-Jurisdictional Transplants: A Comment on Legal Processes and National Culture", Cardozo Journal of Intl.\& Comp. Law, 5, 1997, pp. 51-67.

Jung, H., "Anmerkungen zum Verhältnis von Strafe und Staat", Goltdammer's Archiv für Strafrecht, 1996, p. 507.

Langbein, J. H., "The Influence of Comparative Procedure in the United States", American Journal of Comparative Law, 43, 1995, pp. 545-554.

Langbein, J. H., The origins of adversary criminal trial, Oxford, Oxford University Press, 2003.

Langer, M., "In the Beginning was Fortescue: On the Intellectual Origins of the Adversarial and Inquisitorial Systems and Common and Civil Law in Comparative Criminal Procedure" en Ackerman, B., Ambos K., y Sikiric, H. (eds.), Visions of Justice, Liber Amicorum Mirjan Damaska, Berlin, Duncker \&Humblot, 2016, pp. 273-299.

Langer, M., "From Legal Transplants to Legal Translations: The Globalization of Plea Bargaining and the Americanization Thesis in Criminal Procedure", 45, 2004, Harvard International Law Journal, pp. 1-64.

Langer, M., "Rethinking Plea Bargaining: The Practice and Reform of Prosecutorial Adjudication in American Criminal Procedure", American Journal of Criminal Law, Vol. 33, 2006, pp. 223-300.

Langer M. y Sklansky, D., (eds.) Prosecutors and Democracy. A Crossnational Study, Cambridge, Cambridge University Press, 2017.

Legrand, P., “The impossibility of legal transplants", Maastricht Journal of Eur. \& Comp. Law, 4, issue 2, 1997, pp. 111-124.

Legrand, P., "The same and the different”, en Legrand, P. y Munday, R. (eds.), Comparative Legal Studies: Traditions and Transitions, Cambridge University Press, Cambridge, 2003, pp. 240-311.

Merryman, J.H., "On the Convergence (and Divergence) of the Civil Law and the Common Law", en The Loneliness of the Comparative Lawyer. And Other Essays in Foreign and Comparative Law, Kluwer Law Intl, The Hague, 1999, pp. 17-52.

Monateri, P. G., “The 'Weak Law': Contaminations and Legal Cultures. Borrowing of Legal and Political Forms”, Transnat'l L. \& Contemp. Probs., 13, 2003, pp. 575 y ss., accesible en www.alanwatson.org. 
Nelken, D., "The Meaning of Success in Transnational Legal Transfers", Windsor Yearbook of Access to Justice, 19, 2001, pp. 349-366.

Pérez-Perdomo, R. y Friedman, M., "Latin Legal Cultures in the Age of Globalization", en Friedman M. y Pérez-Perdomo R. (eds.), Legal Culture in the Age of Globalization. Latin America and Latin Europe, Stanford, Stanford University Press, 2003, pp. 1-19.

Sacco, R., "Legal formants: a Dynamic Approach to Comparative Law, American Journal of Comparative Law, 39, 1991, pp. 1-34 y 343-401.

Sarcevic, S., New Approach to Legal Translation, Kluwer Law Intl., The Hague, London, 1997.

Sklansky, D., "Unpacking the Relationship between Prosecutors and Democracy in the United States", en Langer M. y Sklansky, D. (eds.), Prosecutors and Democracy. A Cross-national Study, Cambridge, Cambridge University Press, 2017, pp. 276-299.

Teubner, G., "Legal Irritants: Good Faith in British Law or How Unifying Law Ends up in New Divergences", The Modern Law Rev., 11, 1998, p. 11-32.

Watson, A., Legal Transplants. An Approach to Comparative Law, AthensLondon, The University of Georgia Press, 1993, 2a ed., de la obra publicada en 1974.

Watson, A., "From Legal Transplants to Legal Formants", American Journal of Comparative Law, 43, 1995, pp. 469-476.

Weigend, T., "Should We Search for the Truth, and Who Should Do It?", North Carolina Journal of International Law \& Commercial Regulation, 36, 2011, pp. 389-416.

Wigmore, J.H., "A New Way of Teaching Comparative Law", Journal of the S.P.T.L., 1926, p. 6. 